\title{
NSW ARBOVIRUS SURVEILLANCE WEB SITE
}

\section{Stephen Doggett, Richard Russell and}

Dominic Dwyer

Institute of Clinical Pathology and

Medical Research, Westmead Hospital, Westmead

Viruses transmitted by mosquitoes are known generically as 'arboviruses', and are the cause of considerable human disease across Australia. In New South Wales alone an average of more than 550 cases are notified each year. The resulting morbidity associated with these diseases imposes a significant economic burden on the community. For this reason the NSW Department of Health funds the Arbovirus Surveillance and Mosquito Monitoring Program.

The program undertakes surveillance at over 40 locations throughout the State including: major centres along the coast, several Sydney suburbs, and at inland NSW towns along the principal river systems. The main viruses of concern include the polyarthritidesRoss River virus and Barmah Forest virus; and the encephalitides-Murray Valley Encephalitis virus and Kunjin virus. Arbovirus activity is detected via the isolation of arboviruses from mosquitoes and by flavivirus seroconversion in sentinel chickens. Mosquito populations are also monitored. All laboratory aspects of the program are conducted at the Institute of Clinical Pathology and Medical Research, Westmead Hospital.

The aim of the program is to act as an early warning system so that health authorities can undertake vector control measures and issue media releases warning the public to take self-protective measures against mosquitoes.

For the timely functioning of the program, it is critical that results are disseminated rapidly. However, with the high number of participating bodies (councils, public health units, etc), ensuring this has been difficult. The Internet, especially the World Wide Web, provided an obvious solution; hence the birth of the NSW Arbovirus Surveillance Web site.

The main function of the site is the rapid dispersal of analysed results from the surveillance program. All results are readily available, which means that an individual can look up the results from their own location as well as those from the surrounding region. There is also a considerable amount of space on the site devoted to information on mosquitoes and arboviruses, with much of this information being drawn from the Department of Medical Entomology Web site at http://medent. usyd.edu.au/.

Included on the NSW Arbovirus Surveillance Web site are:

- human disease notifications

- weather information (which influences mosquito abundance)

- publications from the program

- mosquito and arbovirus fact sheets

- related Web sites

- educational training videos

- contacts for further information

- a large range of high-quality photographs.

The NSW Arbovirus Surveillance Web site is a one-stop source of information on arboviruses and mosquitoes.

The site is updated daily. While it has more than 220 pages it is easy to navigate. The navigation icon that appears on the home page is included at the bottom of every page. Currently it is the only Web site that has been constructed for an arbovirus surveillance program in Australia.

The site can be viewed at: http://www.arbovirus. health.nsw.gov.au/ or, for those on the Department of Health Intranet, at: http://internal.health.nsw.gov.au:9320/ arbovirus/index.htm. Please examine the Web site. Your comments are welcomed by the authors. 